\title{
Ion-trap multiple mass spectrometry in pesticide analysis
}

\author{
B. R. Larsen*
}

Environment Institute, Joint Research Centre, European Commission, I-21020 Ispra (VA), Italy

Corresponding author: bo.larsen@jrc.it.

Liquid chromatography multiple mass spectrometry with atmospheric pressure ionisation and ion-trap instruments is a potentially useful technique for structure elucidation of polar pesticides and their degradation products. The major drawback today is the lack of spectral libraries and our limited knowledge on collision induced dissociation processes. The present paper gives an introduction to this area of research and presents interesting examples of fragmentation pathways for protonated and deprotonated ions obtained by atmospheric pressure chemical ionisation (APCl) and electrospray ionisation (ESI).

\section{Introduction}

Modern pesticides and their degradation products are well suited for liquid chromatography atmospheric pressure ionisation mass spectrometry (LC-API-MS) [1-5]. Since most of these compounds are readily soluble in water their runoff into rivers and lakes pose several problems for the supply of clean drinking water. With the recent development of atmospheric pressure ion sources APCI and ESI and ion-trap multiple mass spectrometers $\left(\mathrm{MS}^{\mathrm{n}}\right)$ it has become technically and economically feasible for many laboratories to analyse unknown polar compounds with LC-MS in a similar way to gas chromatography mass spectrometry run in the full scan mode. Structural information on analytes can be obtained by collision induced dissociation (CID) directly in the trap through resonant excitation followed by collisions with helium buffer gas atoms [6]. The MS-MS process can be repeated a number of times and is thus an ideal tool for the study of fragmentation processes and pathways. ESI and APCI produce even-electron molecular ions (EE) which decomposition processes and pathways are much better understood today than just a few years ago. They include simple bond cleavages, cleavages with hydrogen transfer rearrangement and skeletal rearrangements including ring openings. In our laboratory we routinely use ion-trap $\mathrm{LC}-\mathrm{MS}^{\mathrm{n}}$ for structure elucidation purposes of compounds such as photolysis products of environmental chemicals including pesticides [7-9], photooxidation products of volatile organic compounds in aerosol 
<smiles>[Y16]CNc1nc([NH3+])nc(Cl)n1</smiles>

Figure 1. Typical proton migration leading to lateral chain cleavage by $\mathrm{CID}$ of $[\mathrm{M}+\mathrm{H}]^{+}$ions.

[10-12], and metabolites of flavenoids [13]. This paper presents the application of ion-trap LC-MS ${ }^{\mathrm{n}}$ for the study of CID fragmentation of pesticides with typical examples of positive ion fragmentation and negative ion fragmentation. Full descriptions of experimental procedures have been given in details in the above mentioned references.

In a typical experiment, full scan LC-MS spectra are first recorded and the (de)protonated molecule(s) are identified. Next, LC-MS ${ }^{2}$ spectra are recorded by isolating the (de)protonated molecule(s) in the ion-trap followed by CID. The energy required in this process varies between 10 and $40 \%$ of the total available collision energy and is selected to preserve a signal of the precursor ion in the order of 5-10\%. This process can be repeated a number of times by successive isolation of one of the generated ions (product ions) as long as the CID process yields products with the charge preserved on a fragment larger than the instrumental lower mass range limit. The obtained information serve as basis for proposing fragmentation pathways. It is important to notice that the pathways still await confirmation e.g. by extensive isotope labelling studies and are drawn mainly to rationalise the observed fragments.

\section{Positive ion CID fragmentation schemes}

A number of pesticides give strong signals as their protonated molecular ions $[\mathrm{M}+\mathrm{H}]^{+}$by soft API ionisation process such as triazines, phenylureas, and carbamates. Other types of ions can also be obtained from the association of the target compound with solvent molecules. Such van der Waals cluster solvent adduct ions are frequently observed and may confuse the analyst e.g. $\left[\mathrm{M}+\mathrm{nCH}_{3} \mathrm{OH}+\mathrm{H}\right]^{+},\left[\mathrm{M}+\mathrm{nH}_{2} \mathrm{O}+\mathrm{H}\right]^{+}$ and $\left[\mathrm{M}+\mathrm{nCH}_{3} \mathrm{OH}+\mathrm{mH}_{2} \mathrm{O}+\mathrm{H}\right]^{+}$from methanol or $\left[\mathrm{M}+\mathrm{CH}_{3} \mathrm{CN}+\mathrm{H}\right]^{+}$from acetonitrile [14]. The relative intensities of such clusters are typically not very high, and they can often be differentiated from genuine protonated molecule(s) e.g. by applying a small amount of front-end CID energy. Protonated molecule(s) then appear with unchanged intensity, while adduct ions disappear.

CID of $[\mathrm{M}+\mathrm{H}]^{+}$ions $\left(\mathrm{MS}^{2}\right)$ will often yields fragment ions formed by cleavage of lateral chains in the molecular structure. A good example, shown in figure 1, is the forma-

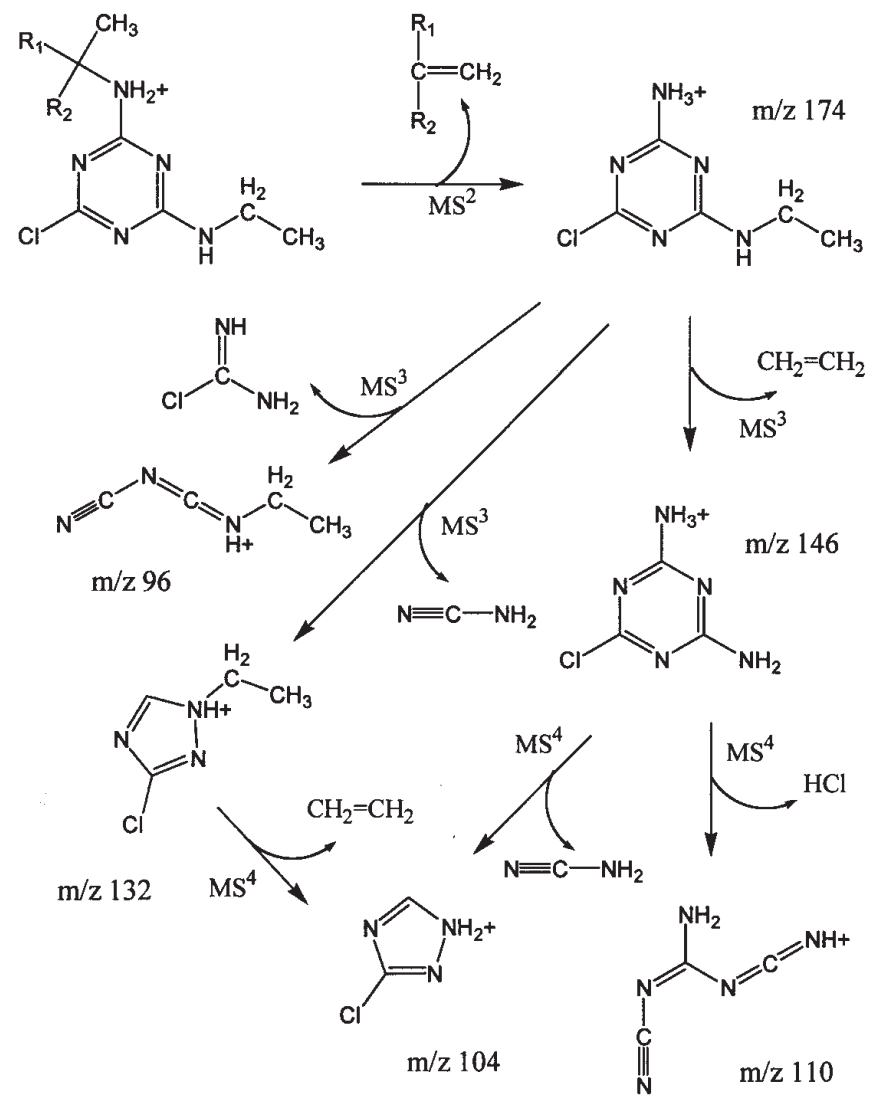

Figure 2. CID (MSn) fragmentation scheme for protonated triazine pesticides.

tion of the ion at $m / z 174$ as base peak from triazine. This ion derives by migration of a hydrogen atom from the methyl group in the $\gamma$-position to the positively charged amino group, which leads to the loss of a disubstituted ethylene molecule [9].

Further $\mathrm{MS}^{\mathrm{n}}$ analysis produces identical results for all investigated triazines and is summarised in figure 2. By $\mathrm{MS}^{3}$ of the precursor ion at $\mathrm{m} / \mathrm{z} 174$ two different dissociation 
processes are evident. The major pathway is similar to the one described above and leads to formation of an intensive ion at $m / z \quad 146$ through the loss of $\mathrm{CH}_{2}=\mathrm{CH}_{2}$ from the $\mathrm{N}$-ethyl lateral chain. The other pathway results in ring rearrangements and leads to formation of a an ion at $\mathrm{m} / \mathrm{z} 132$ and a weak ion at $\mathrm{m} / \mathrm{z}$ 96. Triazine pesticides contain chlorine in their molecular structure. By $\mathrm{MS}^{3}$ analysis of a precursor ion at $\mathrm{m} / \mathrm{z} 176$ containing the chlorine isotope ${ }^{37} \mathrm{Cl}$ it can be confirmed that the ions at $\mathrm{m} / \mathrm{z}, 146$ and $\mathrm{m} / \mathrm{z} 132$ retain the chlorine atom, as opposed to the minor ion at $\mathrm{m} / \mathrm{z} 96$. The pathway is in accordance with Stevensons rule [15] stating that when an $\mathrm{EE}^{+}$ion upon CID fragments into a neutral molecule and another $\mathrm{EE}^{+}$ion following an internal proton migration. The charge is retained at the atom with the highest proton affinity - in this case the amino-group of the ion at $m / z$, 96. The same account for the pathways with elimination of aminonitrile (Fig. 2).

The spectra derived by $\mathrm{MS}^{4}$ of the ion at $\mathrm{m} / \mathrm{z} 132$ contains a single peak at $\mathrm{m} / \mathrm{z} 104$ formed by the loss of $\mathrm{CH}_{2}=\mathrm{CH}_{2}$ from the $N$-ethyl group. This ion can also be formed by $\mathrm{MS}^{4}$ of the ion at $\mathrm{m} / z, 146$ through elimination of aminonitrile. $\mathrm{MS}^{4}$ of the precursor ion at $\mathrm{m} / \mathrm{z}$ 146, also produces a fragment ion at $\mathrm{m} / \mathrm{z}, 110$ formed through elimination of $\mathrm{HCl}$ with a subsequent ring opening. Again evidence for this pathway can be obtained by $\mathrm{MS}^{4}$ analysis of the ${ }^{37} \mathrm{Cl}$ containing isotopic form of the precursor ion, which results in elimination of $\mathrm{H}^{37} \mathrm{Cl}$. The ion at $\mathrm{m} / \mathrm{z}, 132$ formed from the precursor at $\mathrm{m} / \mathrm{z}, 174$ through elimination of aminonitrile has previously been assigned an open-chain structure [9]. However, ring-closure to a five-member ring as depicted in figure 2 after a simple 1,2-proton migration can also be envisaged. Only isotope marking studies can distinguish between the possible structures.

CID $\mathrm{MS}^{2}$ analysis of triazines has been done also by the use of triple-quadrupole mass spectrometry and essentially the same fragments have been observed [16] with tentative assignment of their structures. The multiple mass spectrometry study of these ions [9] has given an experimental support to the proposed structures. A convincing demonstration of the usefulness of $\mathrm{MS}^{\mathrm{n}}$ is the assignment of the structure for the ion at $\mathrm{m} / \mathrm{z} 146$. This fragment may derive from cleavage of lateral chains in the precursor ion or from cleavage of the shortest side-ring followed by ring opening. The fact that $\mathrm{MS}^{4}$ analysis of the $\mathrm{m} / \mathrm{z} 146$ ion shows further loss of $\mathrm{HCl}$ but not of the shortest side-chain strongly point to a structure with an intact triazine ring as depicted in figure 2.

Proton migration after CID of an $\mathrm{EE}^{+}$ion and fragmentation into a neutral molecule and another $\mathrm{EE}^{+}$ion is frequently observed. Yet, other fragmentation pathways are not uncommon. Examples to be mentioned are elimination of methyl radicals from protonated phenylureas [17], methylisocyanate from protonated phenylureas after migration of a methyl group [9], $\mathrm{Cl}_{2}$ from the aromatic ring of protonated diuron [9], $\mathrm{CO}$ from protonated benzylisocyanate [9], and $\mathrm{N}_{2}$ from metamitron after the transformation of a six-member ring into a five-member ring probably through an initial ring opening [9].

\section{Negative ion CID fragmentation schemes}

Acidic pesticides such as e.g. phenoxyacids, nitrocresols and halogenated phenols give strong signals as their deprotonated molecular ions $[\mathrm{M}-\mathrm{H}]^{-}$by API. Just as for protonated ions adducts can be formed from the association of the target compound with solvent molecules. The need for acidic buffers for chromatographic reasons enhance the formation of van der Waals clusters such as e.g. acetate adducts $\left[\mathrm{M}+\mathrm{CH}_{3} \mathrm{COO}\right]^{-}$or formate adducts $[\mathrm{M}+\mathrm{CHOO}]^{-}$, molecular clusters $[2 \mathrm{M}-\mathrm{H}]^{-}$, and solvent adduct ions of the composition $\left[\mathrm{M}-\mathrm{H}+2 \mathrm{CH}_{3} \mathrm{OH}+\mathrm{H}_{2} \mathrm{O}\right]^{-}$from methanol and may confuse the analyst. The relative intensities of such clusters can be high, but they can easily be differentiated from genuine deprotonated molecule(s) e.g. by applying a small amount of front-end CID energy and rather than posing problems in some cases they can even be helpful in differentiating between steric isomers [11].

CID fragmentation pathways of $[\mathrm{M}-\mathrm{H}]^{-}$ions has been less studied than of $[\mathrm{M}+\mathrm{H}]^{+}$ions. One of the main problems is the low electron affinity of carbon atoms and the unlikelihood of retaining a negative charge in the remaining structure after elimination of lateral chains unless electronegative hetero atoms are present.

The phenoxyacid pesticides 2,4-D, MCPA, dichlorprop and mecoprop have the same skeletal structure. The differences lie in the substituent in the 2-position of the ring (methyl or chlorine) and in the carbon in the $\beta$-position to the carboxylic function (hydrogen or methyl). The fragmentation behaviour by CID is quite similar for phenoxyacid pesticides. The $\mathrm{MS}^{2}$ spectra - be that with ion-trap MS [9] or triple-quadrupole MS [18] - show only one type of product ion formed after an internal electron cascade reaction by cleavage of the carboxylic group. The formed phenolate ions and the eliminated lactone are shown in figure 3. Further $\mathrm{CID}\left(\mathrm{MS}^{3}\right)$ of the phenolate ions gives signals for phenoxyacids containing two chlorine atoms (2,4-D and dichlorprop). Carbanion fragments are produced by elimination of $\mathrm{HCl}$ followed by ring opening through a subsequent bond rearrangement and resonance stabilisation as suggested in figure 3 .

More detailed fragmentation processes of $[\mathrm{M}-\mathrm{H}]^{-}$ions are obtained for pesticides containing non-aromatic rings with electronegative hetero atoms. A good example is the $\mathrm{MS}^{\mathrm{n}}$ analysis of deprotonated bentazone (Fig. 4), which shows transformation of a six-member ring into a five-member ring through elimination of sulphur dioxide and cleavage of lateral chains analogue to CID of $[\mathrm{M}+\mathrm{H}]^{+}$ions. In addition to the EE ions please note the interesting formation of two OE ions from $\mathrm{MS}^{3}$ of the $\mathrm{m} / \mathrm{z}, 175 \mathrm{EE}$ ion.

Whereas the multiple MS of halogenated phenols (ioxynil and bromoxinynil) are uninteresting and only yields ions from dehalogenation reactions, the $\mathrm{MS}^{\mathrm{n}}$ spectra of aromatic pesticides containing nitro-groups and hydroxy-groups such as dinoseb and DNOC, are more informative (Fig. 5). 


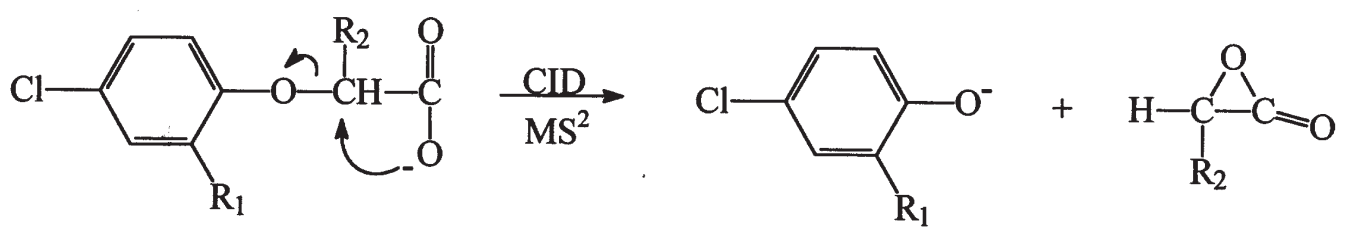<smiles>C=C/C(Cl)=C\C=C=O</smiles>

Figure 3. $\operatorname{CID}\left(\mathrm{MS}^{n}\right)$ fragmentation pathway for deprotonated phenoxy-acid pesticides.

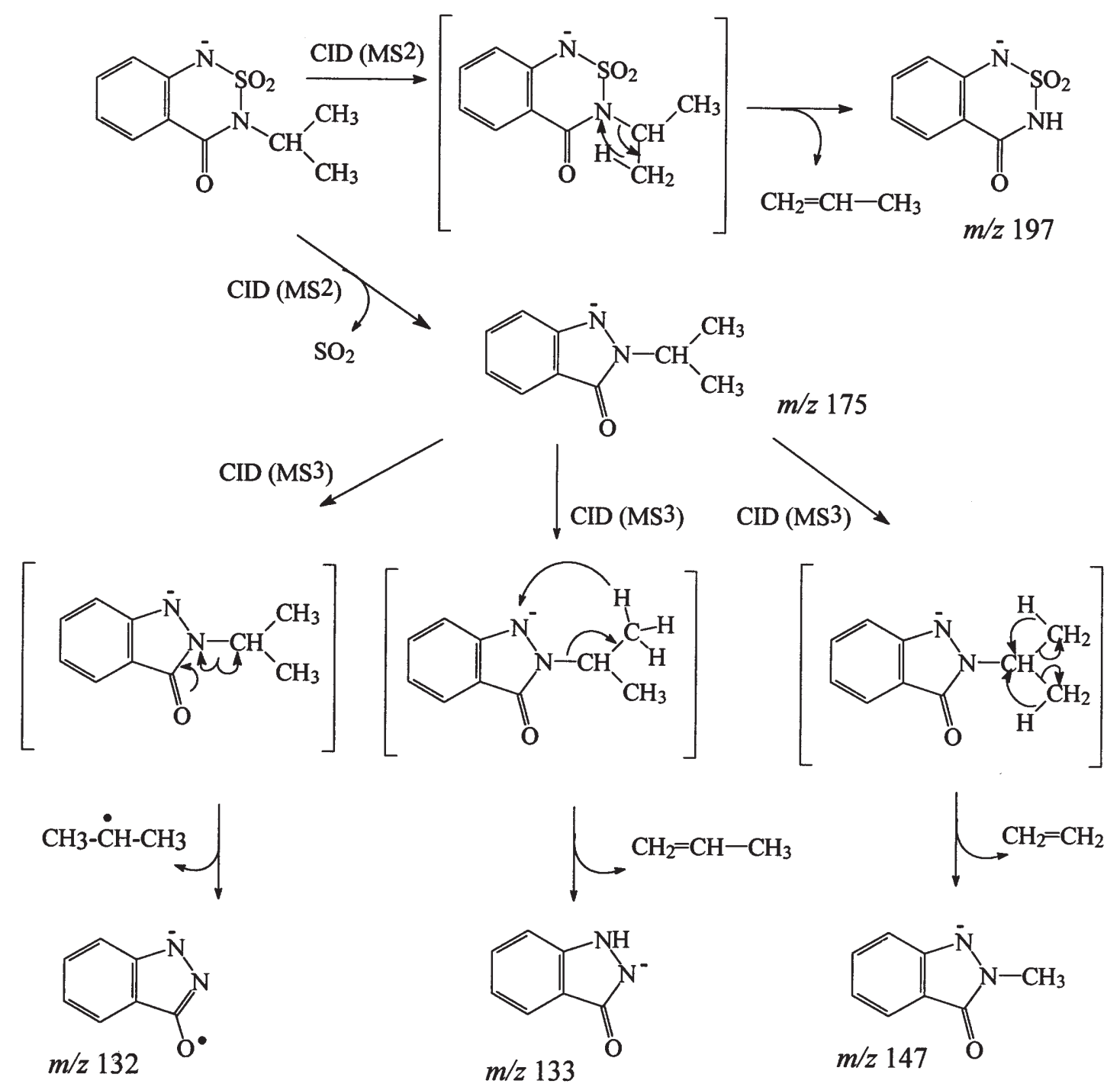

Figure 4. $\mathrm{CID}\left(\mathrm{MS}^{n}\right)$ fragmentation pathway for deprotonated bentazone. 
A<smiles>CCC(C)c1cc([N+](=O)[O-])cc([N+](=O)[O-])c1[O-]</smiles>

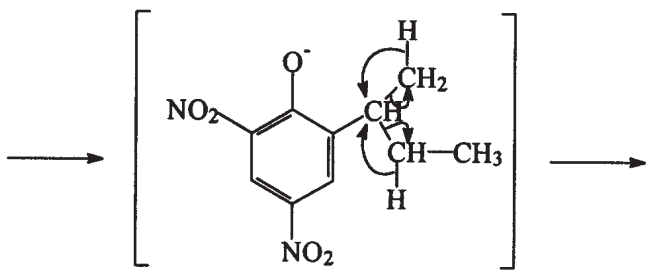

B<smiles>CCC(C)c1cc([N+](=O)[O-])cc([N+](=O)[O-])c1[O-]</smiles><smiles>C=C(C)c1cc(O)cc([N+](=O)[O-])c1[O-]</smiles>

C<smiles>CCC(C)c1cc([N+](=O)[O-])cc([N+](=O)[O-])c1[O-]</smiles><smiles>C=CC</smiles><smiles>CCCCCC(C)C1=CC([N+](=O)[O-])C2CCCC1C2[N+](=O)[O-]</smiles><smiles>CCCCC(C)C1=CC(=O)C=C([N+](=O)[O-])C1=O</smiles>

D<smiles>CCC(C)C1=CC(=O)C=C([N+](=O)[O-])C1=O</smiles><smiles>C[14CH2]C</smiles><smiles>CCCCC1C(=O)C=C(C(C)C)C(=O)C12CCCCC2</smiles><smiles>CCC(C)C1=CC(=O)C=C([O-])C1=O</smiles>

E<smiles>CCC(C)c1cc([N+](=O)[O-])cc([N+](=O)[O-])c1[O-]</smiles><smiles>CC(C)C</smiles><smiles>CCC(C)c1cc([N+](=O)[O-])cc([N+](=O)[O-])c1[O-]</smiles><smiles>CCCC(C)(C)c1cc([N+](=O)[O-])cc([N+](=O)[O-])c1</smiles>

\section{$\mathbf{F}$}<smiles>CCCC(C)(C)c1ccc([N+](=O)[O-])cc1[N+](=O)[O-]</smiles>

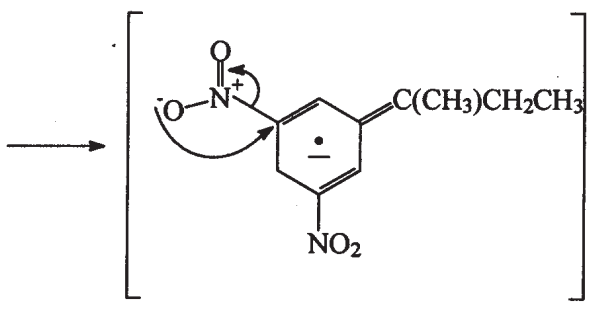<smiles>COC</smiles><smiles>CC=C(C)c1cc([O-])cc([N+](=O)[O-])c1</smiles>

$m / z 192$

Figure 5. CID $\left(\mathrm{MS}^{n}\right)$ fragmentation pathways for deprotonated dinoseb. 
Fragments are observed after cleavage of the lateral chain eliminating 1-propene or $\mathrm{CH}_{3} \mathrm{NO}$, thereby yielding the corresponding nitrocresolate ions (5A and 5B). Interestingly, loss of $\mathrm{NO}^{\bullet}$ yields the corresponding quinone radical where the unpaired electron and the negative charge are delocalised in the ring $(5 \mathrm{C})$. Unexpectedly, $\mathrm{MS}^{3}$ produces an even-electron ion through a second $\mathrm{NO}^{\bullet}$ elimination 5D). A particular behaviour of deprotonated nitrocresol pesticides is their elimination of a hydroxyl radical (and not $\mathrm{H}_{2} \mathrm{O}$ ) by CID. This process has been observed for other phenolic compounds with a hydroxyl group in the ortho-position to an alkyl or amino moiety [19]. A possible mechanism may be the electron attack from the negatively charged ring-oxygen on a hydrogen atom of the ortho-alkyl group (methyl for DNOC and 1-methylpropyl for dinoseb) followed by a homolytic cleavage of the $\mathrm{C}-\mathrm{O}$ bond and structure rearrangement $(5 \mathrm{E})$. Following elimination of an $\mathrm{OH}$ radical further CID leads to the formation of phenolate ions through $\mathrm{NO}$ elimination $(5 \mathrm{~F})$.

The examples on CID fragmentation pathways of protonated and deprotonated pesticides presented in this paper demonstrate the strong potential of liquid chromatography atmospheric pressure ionisation multiple mass spectrometry for structure elucidation. Typical fragmentation mechanisms have been described, which can be applied in future identification of unknown polar compounds such as environmental break-down products and biological metabolites of modern pesticides. Although this area of research has progressed significantly over the past few years our present understanding of CID fragmentation processes still lags behind our understanding of fragmentation by electron ionisation. More work is needed to close this gab.

\section{References}

1. Barceló, D. Applications of LC-MS in environmental chemistry; Elsevier, 1996.
2. Slobodnik, J.; van Baar, B.L.M.; Brinkman, U. A. Th. J. Chromatogr. A 1995, 703.

3. Hogenboom, A. C.; Slobodnik, J.; Vreuls, J. J.; Rontree, J. A.; van Baar, B.L.M.; Niessen, W. M. A.; Brinkman, U. A. Th. Chromatographia 1996, 42, 506.

4. Lacorte, S.; Barceló, D. Anal. Chem. 1996, 68, 2464.

5. Slobodnik, J.; Hogenboom, A. C.; Vreuls, J. J.; Rontree, J.A.; van Baar, B. L. M.; Niessen, M. W. A.; Brinkman, U. A. Th. J. Chromatogr. A 1996, 714, 59.

6. March, R. E. J. Mass Spectrom. 1997, 32, 351.

7. Vialaton, D.; Richard, C.; Baglio, D.; Paya-Perez, A.B. J. Photochem. Photobiol. A 1998, 119, 39.

8. Vialaton, D.; Baglio, D.; Richard, C.; Skejo-Andreasen, H.; Paya-Perez, A. B. Fresenius Environ. Bull. 2000, in press.

9. Baglio, D.; Kotzias, D.; Larsen, B. R. J. Chromatogr. A 1999, 854, 207.

10. Glasius, M.; Duane, M.; Larsen, B. R. J. Chromatogr. A. 1999, $833,121$.

11. Glasius, M.; Di Bella, D.; Lahaniati, M.; Calogirou, A.; Jensen, N. R.; Hjorth, J.; Kotzias, D.; Larsen, B. R. Environ. Sci. Techn. 2000, 34, 1001.

12. Larsen, B. R.; Di Bella, D.; Glasius, M.; Winterhalter, R.; Jensen, N. R.; Hjorth, J. J. Atmos. Chem. 2000, in press.

13. Justesen, U.; Arrigoni, E.; Larsen, B. R.; Amadò, R. Food Sci. and Technol. 2000, 33, 1001.

14. Sabik, H.; Jeannot, R. J. Chromatogr. A 1998, 818, 197.

15. Willoughby, R.; Sheeman, E.; Mitrovich, S. A Global View of $L C / M S$; Pittsburgh, Pennsylvania: Global view publishing, 1998.

16. Volmer, D. A. J. Chromatogr. A 1998, 794, 129.

17. Yinon, J.; Vincze, A. Int. J. Mass Spectrom. 1997, 167/168, 21.

18. Köppen, B.; Spliid, N. H. J. Chromatogr. A 1998, 803, 157.

19. Astratov, M.; Preiß, A.; Levsen, K.; Wünsch, G. Int. J. Mass Spectrom. 1997, 167/168, 481. 